\title{
Structured Visual Learning and Stimulation in School: An Intervention Study
}

\author{
Gunvor B. Wilhelmsen ${ }^{1}$, Marion Felder ${ }^{2}$ \\ ${ }^{1}$ Faculty of Education, Arts and Sports, Western Norway University of Applied Sciences, Bergen, Norway \\ ${ }^{2}$ Department of Social Sciences, Koblenz University of Applied Sciences, Koblenz, Germany \\ Email: *gunvor.birkeland.wilhelmsen@hvl.no
}

How to cite this paper: Wilhelmsen, G. B., \& Felder, M. (2021). Structured Visual Learning and Stimulation in School: An Intervention Study. Creative Education, 12, 757-779.

https://doi.org/10.4236/ce.2021.124054

Received: February 13, 2021

Accepted: April 11, 2021

Published: April 14, 2021

Copyright $\odot 2021$ by author(s) and Scientific Research Publishing Inc. This work is licensed under the Creative Commons Attribution International License (CC BY 4.0).

http://creativecommons.org/licenses/by/4.0/

\begin{abstract}
Background: The 4-year project Securing education for children in Tanzania aims at improving education through assessment and educational training in visual functions such as visual acuity, accommodation, fixation and ocular-motor function in school age children by trained teachers. This article describes and analyzes a 3-week vision intervention and its outcome on the pupils with regards to selected visual functions and reading speed. Objective: To investigate whether structured visual stimulation improves visual functions and reading speed in $5^{\text {th }}$ grade pupils at an elementary school in urban Tanzania. Methods: A quasi-experimental/intervention study with pre-and post-test following visual stimulation intervention involving a vision group ( $\mathrm{n}$ $=21)$ and a control group $(n=14)$. Results: The pupils who received structured vision stimulation for 3 weeks, 1 hour per day improved visual functions and their reading speed. Conclusion: Structured visual training done by highly qualified teachers has an impact on visual functions and reading speed. More research has to identify the benefits, challenges and consequences for education and service delivery.
\end{abstract}

\section{Keywords}

Visual Stimulation, Visual Training, Improved Vision, Reading, Education, Learning

\section{Introduction}

The main research question of this study is whether structured stimulation through vision-lessons in school will influence pupils' vision qualities and reading speed. The rationale for the study is the fact that most activities in school are dependent on intact visual functions. There are estimates that in over $70 \%$ of 
school content and activities vision is involved (Narayanasamy et al., 2016) thus problems with visual functioning can have detrimental effects on reading and learning, if they are not discovered and attended to. Problems in the area of vision do not need to be severe or at the level of a medical classification of visual impairment to impact education, such as reading and writing. Some problems may not be solved with eyeglasses or with eyeglasses alone. For some visual conditions to improve, structured vision exercises might be necessary (Wilhelmsen \& Felder, 2020; Felder, Wilhelmsen, \& Schneiders, 2021).

Children's development grows on constructive inputs, stimulation and experience (Björklund \& Causey, 2017). This is also the case for their visual attention, perception and ocular motor functions. These are skills, which among others, are important for their cognitive functioning, learning and reading. Researchers from different disciplines have developed theories on how to stimulate and train specific sensory and ocular motor functions (Barraga, 1964; Lane, 2005; Sterner, 2004; Cyvin \& Wilhelmsen, 2008; Coetzee \& Pienaar, 2013; Wilhelmsen \& Knudsen, 2020).

Since 2008 the Western Norway University of Applied Sciences, HVL, in Norway offers a post BA program in Vision for Reading and Learning as a 30-credit continuing education program which focuses on training and strengthening visual functions through structured intervention.

In 2016 Western Norway University of Applied Sciences, HVL, together with Koblenz University of Applied Sciences, Germany, and Patandi Teachers College of Special Need Education, Tanzania, received funding for the project Securing Education for Children in Tanzania with focus on children's vision for reading and learning based on the original program at HVL. The program was funded by The Research Council of Norway, NFR, for the period of 2017-2021. Teachers in Tanzania completed the 30-credit CPD-course Vision for reading and learning with lectures and supervision from researchers and vision specialists from HVL and Koblenz University of Applied Sciences. The overall project goal was to improve education for children in Tanzania through improved visual functioning. Most of the teachers enrolled in the project had a background in special needs education, many in the category Visual Impairments and Blindness (Felder, Wilhelmsen, \& Schneiders, 2021).

Teacher students in this project had to develop a structured training plan for the pupils of standard 5 in the project school. The plan was based on theories and ongoing assessment and they had to conduct individual vision lessons for stimulation. The students' practical work was part of the course requirement. In order to evaluate the project outcome, it was necessary to determine whether the program benefitted the children. Thus, the practical work was data and assessment driven and was conducted as a quasi-experimental intervention study with a control group. The intervention was organized by the vision teacher specialists and researchers who supported and supervised the students throughout the program. The data were analysed for answering the question of what kind of effect the intervention had on the participating pupils' vision and their reading speed. 
The next Section 2 outlines the theoretical framework of the study supporting the rational for the study and the research questions. Section 3 describes the methodology, including the phases of the study and intervention, the participants and ethical considerations. These sections are followed by an illustration of the results of the study (Section 4) and the discussion of the results (Section 5). In Section 6, implications for practice are discussed which is followed by a description of the limitations of the study (Section 7). The article presents a conclusion in the final section (Section 8).

\section{Theoretical Framework}

Vision is important for discovering the surroundings, for awareness, for collecting information about relationships of objects and people and for several cognitive and motor actions. Through vision children learn to interact with people and discover the external world (Björklund \& Causey, 2017). Schiller (2010) found that the neurological pathways are formed and strengthened through experiences and repetitions of actions. These pathways may improve even after puberty because substantial neural plasticity remains throughout life (Lillard \& Erisir, 2011).

Visual acuity, VA, is a main vision quality and the most frequently examined vision function evaluated in children. Normally it is measured at six or three meters, but it is important to measure visual acuity at a reading distance to see if the child is capable to regulate, accommodate, the lens for keeping a clear focus at near. If this is not the case, the child will struggle with all near tasks, including reading (Wilhelmsen, 2012; Wilhelmsen, Aanstad, \& Leirvik, 2015).

Poor ocular motor qualities and capacities will lead to unclear vision inputs, double images and visual fatigue. Functions like accommodation and convergence are needed for effective change of focus from distance to near and for keeping the focus at near clear for long periods of time. Many brain areas are involved in the complexity of executing normal and effective eye movements like precise saccades, gaze jumps, and steady fixations. An ocular motor deficiency leads to poor quality of binocular coordination of saccades in a range of tasks and may be due to immature mechanisms responsible for normal ocular motor functions (Wilhelmsen, 2000; Bucci, Brémond-Gignac, \& Kapoula, 2008).

Vision is also influenced by activities. This is shown through myopia research where researchers find that prolonged time spent with near work affects the degree of myopia (Fernández-Montero et al., 2015; Lin et al., 2014) and that many hours of doing out-door-activities can protect or prevent the development of myopia (Deng, Gwiazda, \& Thorn, 2010).

Kelly et al. (2019) explain how important it is to reach good binocular stability during childhood. If the eyes are not working well together, the weakest eye may turn amblyopic, which means it will lose visual acuity. Also, an instable vergence/convergence will limit the binocular vision. Children with good binocular vision show better performance in practical manipulation tasks than those using 
one eye only (Alramis, Roy, Christian \& Niechwiej-Szwedo, 2016). It is often said that both too much or too little of something can be wrong, and this is even the case when it comes to structured stimulation. In general, it was found that if exercises are not designed to fit the stage of development, they can do more harm than good (Harlow 1959 ref. in Björklund \& Causey, 2017). In the book Eyes for learning, Orfield (2007) shows how pre-school children do not only turn myopic from looking at screens for too long, they also develop binocular problems. This occurs due to immature binocularity for long-lasting near-work tasks not suitable for their level. When the task of convergence is too difficult to master, one eye will be "excluded" and turn amblyopic. The result may be reduced visual acuity and an exophoria or esophoria (the eye turns outward or inward). These problems will often influence the learning process negatively. It is not always easy to follow Schiller's (2010) advice for teachers of performing face-to-face interactions with pupils. In developed countries, at school, pupils increasingly attend to their screens instead of their teacher. In countries like Tanzania, one of the challenges for the teachers is the high number of pupils in class which makes it difficult for teachers to give each pupil the needed close attention. There is evidence that structured vision exercises through 1:1 interaction can result in better outcome of visual functioning. For example, through an 18-week program once per week during the school day Coetzee \& Pienaar (2013) show that visual therapy for 8 to 9 -year-old children with a developmental ocular coordination disorder results in significantly better ocular motor control.

The main treatment procedure of binocular problems among children has been to patch the best eye for strengthening the ocular motor activities and capacity of the weaker eye. This is found to be less effective than expected because many children do not reach the important binocular functioning trough this procedure (Birch, 2013).

In the following intervention study, it was tested whether $5^{\text {th }}$ grade pupils at an elementary school in urban Tanzania reach not only better monocular visual acuity but even improve the binocularity following structured vision lessons' in school. In addition, it was investigated whether the pupils improved their reading speed following intervention in visual functions.

\section{Methods}

This quasi-experimental intervention study was conducted to see if structured, individualized vision lessons influence pupils' vision and their reading. The intervention took place at a government primary school in a large city in Tanzania. The intervention was part of the requirements for the students to fulfil their practical vision teaching. The school has had an ongoing cooperation with HVL for many years. Although, the children's first language was Kiswahili, the language of instruction at the school is English. Thus, communicating with the children was possible for the international project members. Children attend the school from different areas of the town, and some are boarding. Socio-economically, the pupils' families must be able to pay for food and/or accommodation for their 
child to be able to attend the school.

\subsection{Participants}

The participants come from three classes of pupils in Standard 5 and they are usually between 10 and 11 years old. All pupils with parental permission ( $\mathrm{n}=$ 104) were assessed at the end of Standard 5. Twenty-one pupils with vision disturbances were chosen as the vision-group and offered vision lessons, Figure 1 . Some had reduced visual acuity at near or distance, weak accommodation or convergence and/or disturbed binocular vision. When evaluating the assessment-results, some other 14 pupils with milder vision problems, were identified and chosen as the control-group. The remaining pupils $(\mathrm{n}=71)$ are in the following named the other pupils and serve as a normal group, although even some of them have smaller vision disturbances.

The vision group together with the control group represented $33 \%$ of all the assessed pupils $(\mathrm{N}=104)$. Each group had pupils from the three parallel classes of standard 5 .

The mean age in the vision group was 11.32 years, the control group was slightly younger with a mean age of 11.13 years and the other pupils mean age was 10.98 years. This means that the vision group was not struggling with vision disturbances because of immature vision due to younger age. The age distribution is shown as percent of age-groups in each sample, Figure 2. The goal was to compare the pupils in the three groups on vision functions and reading speed.

\subsection{Phases of the Study}

The children in the vision group and the control group were followed for one year. First, all the 104 pupils were assessed in the end of standard 5, in the autumn, which is the last part of the school year (Phase 1).

Later, in the spring of standard 6, the vision-group had a pre-test (Phase 2) directly prior to the three weeks of intervention with the vision lessons (Phase 3). These lessons took place in school during the normal school hours and went on for 40 - 50 minutes each day during the three weeks. The intervention ended with a post-test (Phase 4). Half a year later, in the autumn of standard 6, both the vision-group and the control-group were retested (Phase 5) (Figure 3).

Figure 3 shows the four test/assessment periods, Phases 1, 2, 4 and 5, where the same test items were used. Phase 3 is the intervention period, consisting of lessons for the vision group.

\subsubsection{Phases 1 and 2: Assessment of All Children and Pre-Test of the Vision Group}

Standardized vision tests and methods were used in Phase 1 and 2 to assess visual functions, Table 1. For visual acuity at distance and near, a standardized vision test for children, the LEA chart was used because the symbols (circle, house, apple and square) are child friendly and easy to understand in all cultures. It is also an advantage that the test-distance for measuring distance visual acuity is 
developed for use of 3 meters instead of the standard 6 meters. A shorter distance makes it easier for children to keep their attention on the screening items.

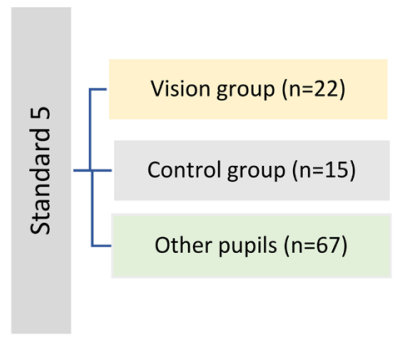

Figure 1. The Standard 5 students $(\mathrm{n}=104)$ were divided in three groups: 1) the Vision-group who got lessons with vision exercises, 2) the control-group who also had some vision disturbances but no exercises and 3) the other pupils.

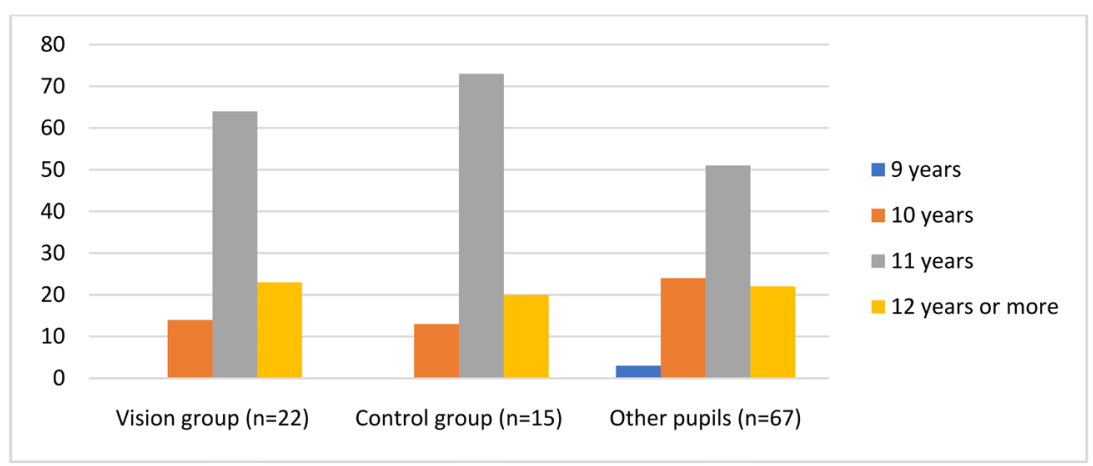

Figure 2. The age distribution among pupils in the three groups in percent.

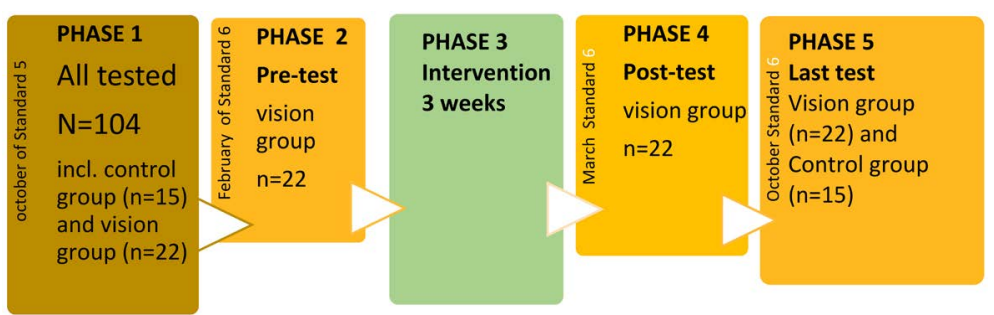

Figure 3. The one-year procedure with all phases.

Table 1. The tests used in the screening program.

\begin{tabular}{ccc}
\hline Functions & Test & Comments \\
\hline Visual acuity & LEA near $(40 \mathrm{~cm})$ & Both with 5 symbols per line \\
& LEA distance $(3 \mathrm{~m})$ & Ruler and a fixation object \\
Occommodation: push up method & Convergence: push up method \\
Stereo vision: the fly test & With 3D-glasses \\
Three dot-test $(3,2,1$ meter $)$ & With polarizing filters \\
Colour vision & Ishihara & Stretched arms \\
Eye dominance & Hole in the card test: distance $3 \mathrm{~m}$ & Bended arms \\
Reading & Hole in the card test: near $40 \mathrm{~cm}$ & Recorded \\
\hline
\end{tabular}


The student teachers were trained to assess accommodation and convergence with standardized push-up methods using a ruler and a fixation object. For the stereovision the Fly-test was chosen and for support for evaluating the binocularity a Three-dot-test was used.

Vision dominance was checked with the traditional Hole-in-the-card test (Miles, 1929) which is normally completed on a 3-meter distance or more. Here the test was adapted to near for evaluating the near dominant eye. The same test is used but the card is held like a book only $40-50 \mathrm{~cm}$ away from the eyes. In this way, it is possible to evaluate whether the pupil has the same dominant eye at near as at a longer distance.

All pupils had to read a text that was deemed appropriate for their grade and level and the reading speed was measured. This was done once for all pupils, for the control-group twice and for the vision-group four times, Figure 3. The texts used were comparable both in font, letter size, vocabulary and content. The pupils were all recorded during reading.

\subsubsection{Phase 3: The Intervention: The Vision Lessons}

The pupils received their intervention/vision lessons individually. Each pupil was paired with one to two vision teacher students during each lesson. The teacher students had to help each other in preparing the lessons and observe each other during the intervention followed by discussions and reflections about the activities afterwards.

Because motivation and happiness are important elements for learning, the teachers had to find a variety of motivating exercises suitable for each pupil and for their individual visual disturbances.

The lessons took place in a large, bright and airy room which was divided with moveable dividers into separate areas. Three or four groups, pupils and teachers, could work in one room at the same time.

The main purpose of the lessons was to strengthen the eye movements so the binocular activities could be normalized and even the sensor capacities could improve. Strengthening accommodation and convergence are essential for getting a clear single image of near symbols.

Table 2 shows how the lessons were divided in two main parts, a) the warm-up session and b) the individualized exercises:

Table 2. Elements and principles for vision lessons.

\begin{tabular}{ccc}
\hline Ocular motor functions & Warm-up exercises & Individualized exercises \\
\hline Accommodation & $\mathrm{X}$ & $\mathrm{X}$ \\
Convergence & $\mathrm{X}$ & $\mathrm{X}$ \\
Saccades & $\mathrm{X}$ & $\mathrm{X}$ \\
smooth pursuits & $\mathrm{X}$ & $\mathrm{X}$ \\
visual attention & & $\mathrm{X}$ \\
Eye-hand coordination & $\mathrm{X}$ \\
Balance & $\mathrm{X}$ \\
\hline
\end{tabular}


1) The first 10 - 15 minutes were a warm-up session where teacher and pupil sat at a desk opposite each other. In this position the teacher showed small cards with letters, figures or numbers quickly and the pupil had to tell what they saw. The exercises were performed with the pupil's head in a straightforward, fixed position with only the eyes moving. The teacher changed the angle, distance and tempo of the cards shown so the pupil's eyes had to deal with variations in accommodation, convergence and saccades. Even exercises with smooth pursuits were presented. The warm-up session is an important start for pupil's awareness on head position and their ocular motor functions. These exercises are fundamental for strengthening ocular motor activities and binocularity. The warm-up session also provides the teacher with opportunities to observe changes in the pupil's reactions, endurance and capacity, which may impact the content and objectives for the remaining lesson.

2) Several pupils' eyes were not working together sufficiently over time, so the teacher students had to work alternately with each eye alone and in-between with both eyes together. For the remaining part of the lesson, following the warm-up sessions, the teacher had to develop a variety of exercises addressing the individual problems, which were discovered during the assessment process or during each lesson. Accommodation and convergence could be stimulated from a longer distance with figures/symbols held some meters away which had to be looked at before finding the same figure/symbol on a chart or card on a reading/closer distance. Also, here it could be necessary to change between monocular and binocular tasks and develop the level of a pupil's reaction with tempo, size, angle and figure complexity. Some pupils needed to work on strengthening the eye muscles for looking left, up, right or down perhaps more than in other directions. A lot of different materials were used: puzzles, games, letter and number cards and pictures. The teacher students also collaborated with the classroom teachers to incorporate school content and materials in the vision lessons. Some teacher students developed visual exercises involving body movement and moving objects, challenging the pupil's visual attention in the visual fields. The exercise book from Lane (2015) was also used as an inspiration for the teachers for their preparations. Teacher students also assessed what kind of activities and materials were motivating to the pupils and used them during the lessons.

The teachers had to observe and constantly evaluate how the pupils reacted and handled the visual challenges connected to the tasks and develop the exercises, so the level was on the border of what the pupil was able to cope with. The goal was to lift them to a higher visual level.

\subsubsection{Phases 4 and 5: Post-Test and Last Test}

The vision group was assessed immediately following the intervention and again re-tested together with the control group 6 months after intervention. Each time the same assessment materials were used for testing. The purpose was to see whether the vision functions and reading capacity had an immediate effect (Phase 4: post-test) and even a long-term effect in comparison with the control 
group (Phase 5: last test).

\subsection{Ethics}

All parents received an information letter with a form to sign that their child could be assessed. Those who were invited to the vision group also had to give permission for the child to attend and to be photographed or videotaped during the project. Some parents did not want their child to be assessed, others allowed their child to join the lessons, but did not want them to be filmed or photographed.

Some of the classroom teachers at the school were also teacher students in the Vision for reading and learning course. It was agreed that they would follow up with pupils from the vision group and control group in case the children needed further intervention after the study was completed. All children were referred for further eye health care if significant refractive error and/or low vision was discovered during the assessment process.

It was also arranged with the classroom teachers that pupils could leave the classroom for the vision lessons and that the content of the missed school lesson was communicated to the pupils so that they did not have disadvantages during exams. All members of the study group had to be very flexible and adjust their plans according to the child's schedule in school.

\section{Results}

In this section the results for visual acuity, accommodation and convergence are presented together with the pupils' reading speed.

\subsection{Visual Acuity}

The three groups varied in visual acuity (VA) when looking at their mean results. In the first test, Phase 1, the vision group had the weakest VA on each eye and binocularly compared to the control group. The other pupils, who were not placed in the vision group or control group, had a mean distance VA above 1.0 monocularly and binocularly, Figure 4. This is seen as a normal result. The control group had a slightly reduced distance VA mean on each eye but reached 1.0 binocularly. For the vision group all three measurements were under 1.0, when looking at objects on a 3-meter distance, Figure 4(b).

When it comes to the near VA, all means are normal for those who were not chosen $(n=66)$ to be part of the control group or the vision group except for the left eye where the mean result was 0.98 . Both the control group $(\mathrm{n}=15)$ and the vision group $(\mathrm{n}=22)$ had reductions in their near VA although the vision group was the weakest, Figure 4(a).

Normally children have a better distance VA due to the fact that accommodation needs longer time to develop and immature near VA is common among pupils struggling with reading (Sterner, 2004). This is also the case among these pupils here in Standard 5, they have a better distance VA than near VA, but the vision group is falling behind on both distances the most, Figure 4(a) and Fig- 
ure 4(b).

The results of near and distance VA are distributed differently in the three groups in Phase 1, This is illustrated with the boxplot graphs in Figure 5(a) and Figure 5(b). In the group of other pupils there are even pupils who reach a VA of 2.0, but also some who only have a VA of 0.5. Those with the lowest results are found, both at near and distance, in the vision group, except for one pupil in the control group who has the lowest near VA of all.

One year went between Phase 1 and Phase 5. In the middle of this year the vision group got three weeks with individual structured vision lessons. The pupils in the control group had no special intervention in this period. Both groups were screened again with the same tests, Phase 5. The graphs in Figure 6, show how the vision group, yellow bars, has developed their vision acuity on each eye (od-right eye and os-left eye) and their binocular visual acuity (ou) in this time. The changes are seen in the difference between the fill bars and the striped bars.

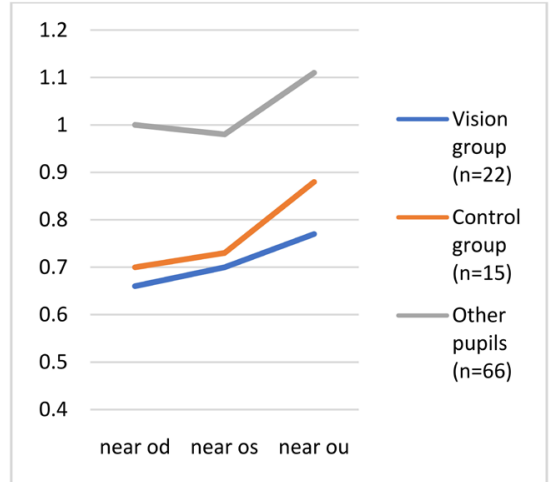

(a)

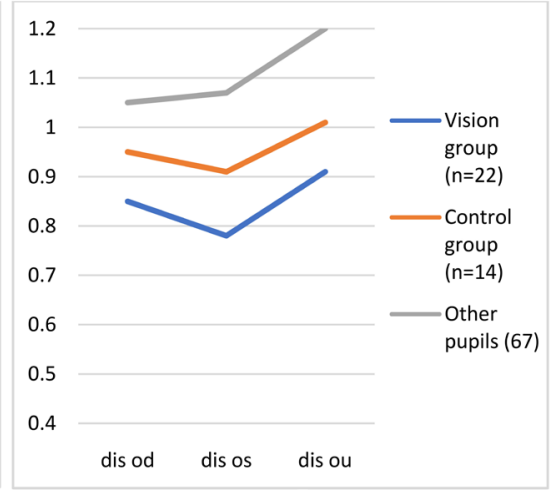

(b)

Figure 4. The mean group results for each eye (od = right, os = left) and binocularly (ou) for (a) near VA and (b) distance VA for the vision group, control group and the other pupils on the first screening, Phase 1. (a) Near VA for the three groups; (b) Distance VA for the three groups.

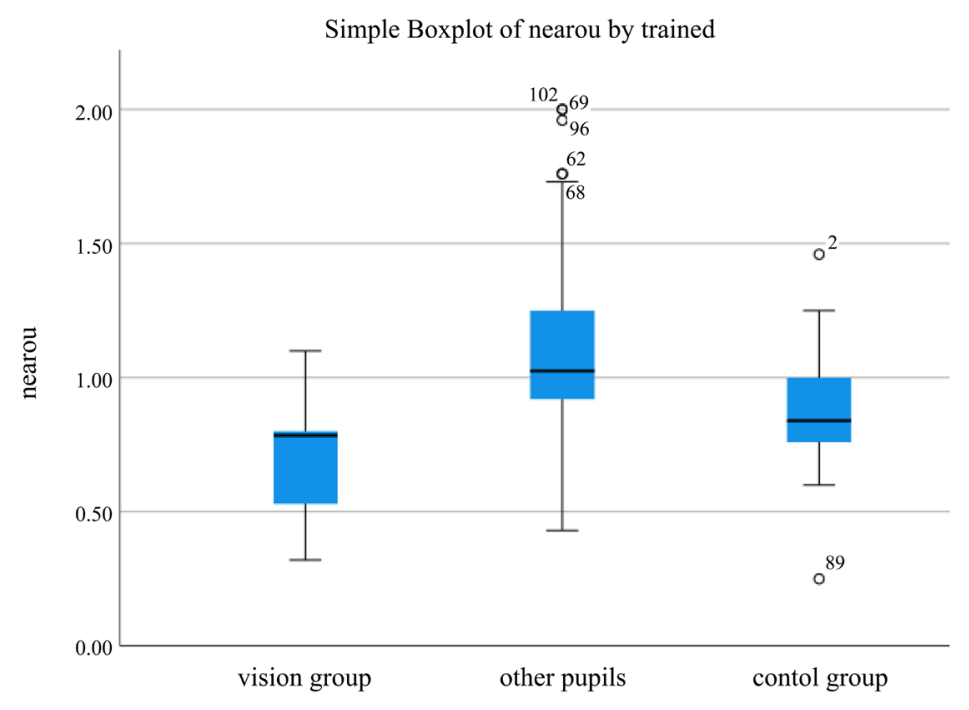

(a) 


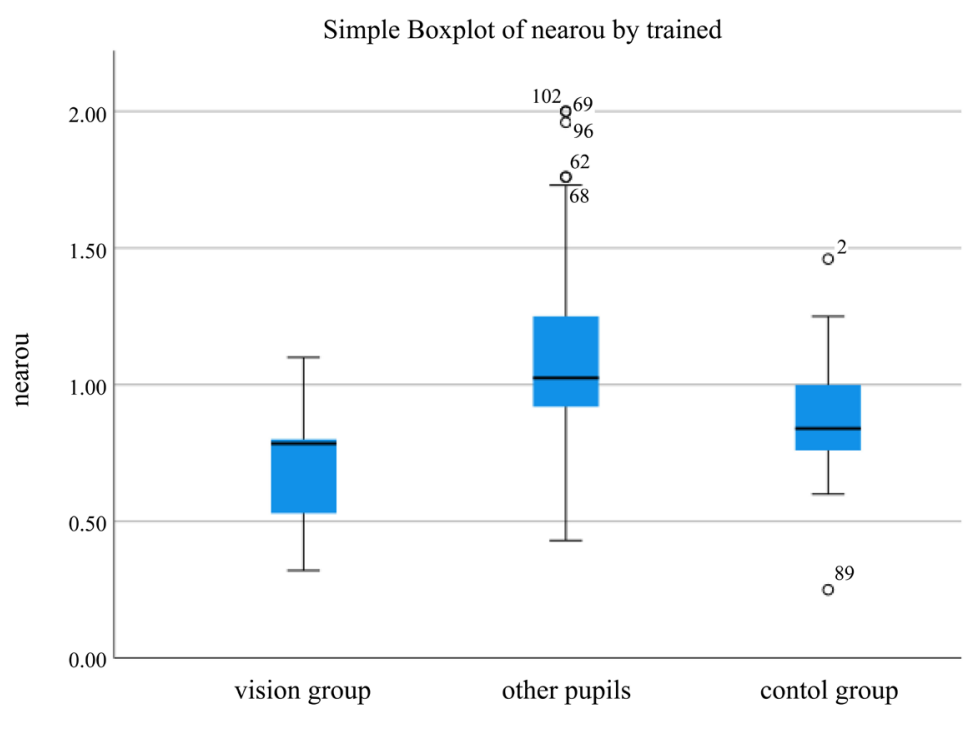

(b)

Figure 5. The distribution of binocular VA at (a) near and (b) distance for the three groups. Vision group $(n=22)$, other pupils $(n=66)$, control group $(n=$ 15). (a) Binocular near VA; (b) Binocular distance VA.

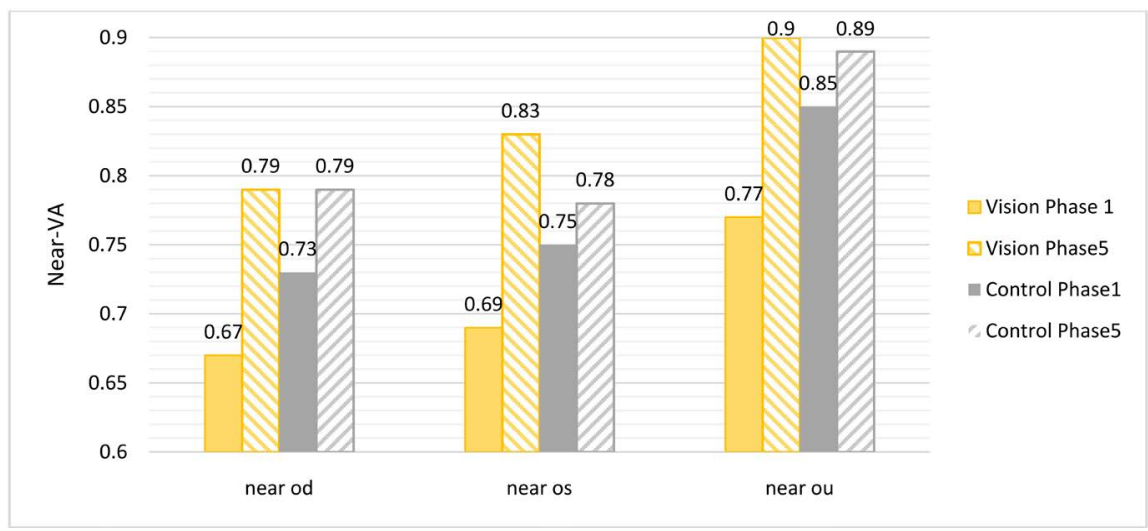

Figure 6. The mean near-VA for od (right eye), os (left eye), ou (both eyes) in the start of the project, marked with Phase 1 , and the year after, marked with Phase 5, for the vision group $(n=22)$ and control group $(n=15)$.

Because vision is developing through the years in school, also the control group, grey bars, had some positive changes in their near VA. But the gap between the groups in Phase 1 is much larger, filled bars, than the results of Phase 5 , striped bars. Half a year after the intervention the vision group has reached the same VA level at near as the control group.

\subsection{Accommodation and Convergence}

To manage the work of changing focus from an object at distance to an object or symbol at near, the eye lenses must accommodate. At the same time the two eyes must be directed towards the very same spot. Near work requires good accommodation, between 4 and $8 \mathrm{~cm}$, for being able to see clearly over time during near activities like reading, writing and drawing. At the same time, and towards 
the same distance, the convergence must stay strong enough over time to hinder double vision. The accommodation and convergence capacity are here measured in $\mathrm{cm}$.

The means for the three groups in Phase 1 show that the vision group had a weaker accommodation and convergence than the two other groups, Figure 7.

In Phase 1 the mean of accommodation and convergence were better in the control-group than in the vision group. In the control group the values were closer to the border value of $8 \mathrm{~cm}$. The other pupils had the best mean of accommodation, but the boxplot reveals that even several pupils in this group have challenges with their accommodation capacity, Figure 8(a).

The accommodation mean for the vision group was $13 \mathrm{~cm}$, but the boxplot in Figure 8(a) shows that the accommodation results are spread from $7 \mathrm{~cm}$ to 38 $\mathrm{cm}$ in this group. So, several pupils are struggling with focusing clearly at near. The control group has a mean of $10 \mathrm{~cm}$ and the participants in this group are close to this result, Figure 8(a). Although the other pupils $(\mathrm{n}=66)$ have the best mean their results are spread on a larger scale and four outliers have a really weak accommodation.

Also, when it comes to convergence, the mean value is the highest in the vision group, with $11 \mathrm{~cm}$, but the results are spreading from $4 \mathrm{~cm}$ to nearly $20 \mathrm{~cm}$ with two outliers going even higher, Figure $8(\mathrm{~b})$. With a mean of $9 \mathrm{~cm}$, the control group has results spreading from $4 \mathrm{~cm}$ to $18 \mathrm{~cm}$. In this group there are no outliers. Although the group of other pupils has a mean of $8 \mathrm{~cm}$ for convergence, some of the pupils have an abnormal convergence higher than $8 \mathrm{~cm}$ and some outliers in this group of pupils have huge problems with their convergence.

The boxplot in Figure 9 illustrates how accommodation and convergence are connected to each other. When there is a weak accommodation there is mostly a disturbed convergence. For the intervention it is of huge importance to stimulate and strengthen these functions because they influence all near activities. Through a steady accommodation at near, the visual inputs will be clearer, and this is normally measured as a better near VA. At the same time a good capacity of convergence will create two overlapping images to the brain which will be perceived as a single picture.

The other pupils were tested only once, in Phase 1. Their accommodation means result of $8.69 \mathrm{~cm}$ is illustrated with the brown bar in Figure 10. The yellow bars are the accommodation result for the control group in Phase 1 and Phase 5. The vision group was screened four times: Phase 1 with all the others, Phase 2 which was the pre-test before the intervention, Phase 4: the post-test after intervention and Phase 5 half a year after the intervention. The results from the vision group are all the green bars. The best accommodation was reached just after the intervention. Here the vision group has even a better mean than the other pupils reached in Phase 1 (brown bar).

Half a year after the intervention, the accommodation for the vision group was reduced to $10.33 \mathrm{~cm}$, although this is still better than before the intervention which was $11.64 \mathrm{~cm}$. 


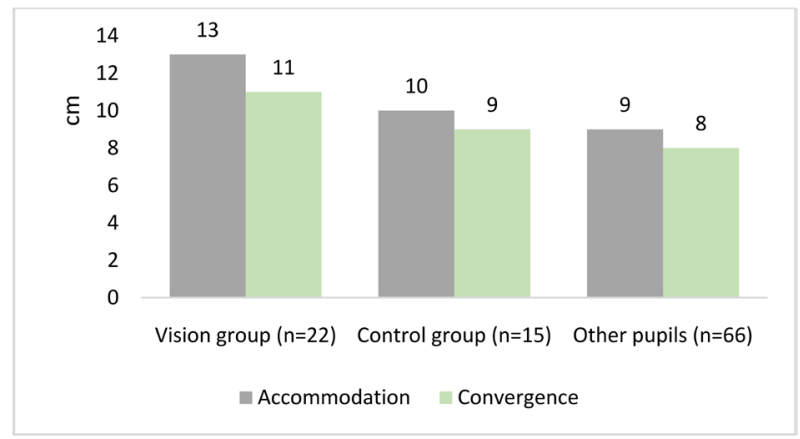

Figure 7. The mean of accommodation and convergence capacity measured in $\mathrm{cm}$ for the three groups.

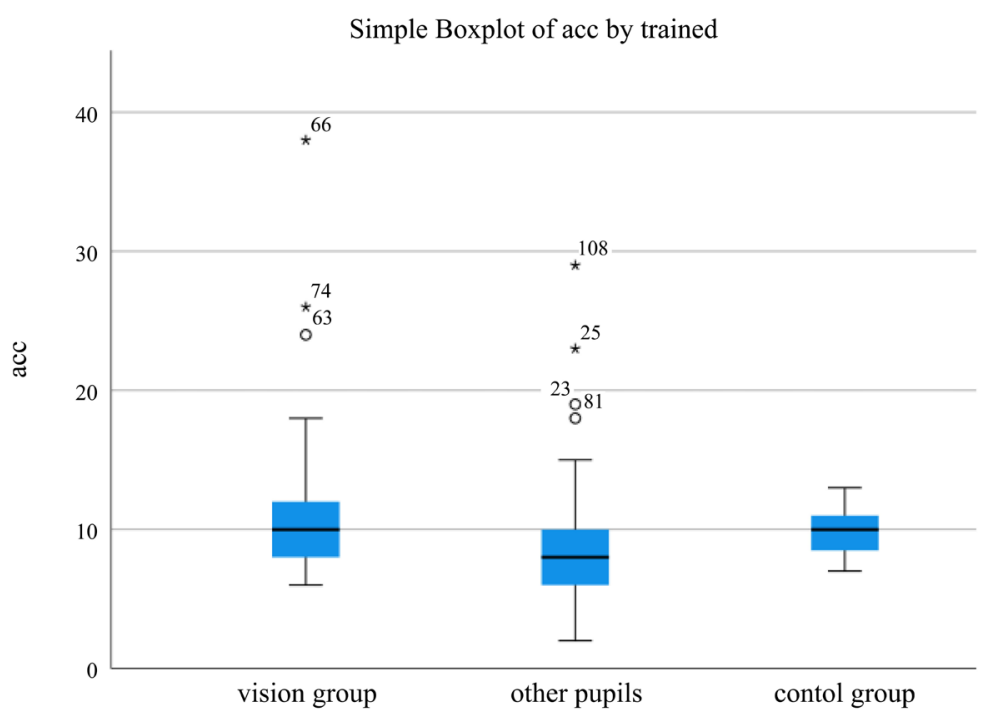

(a)

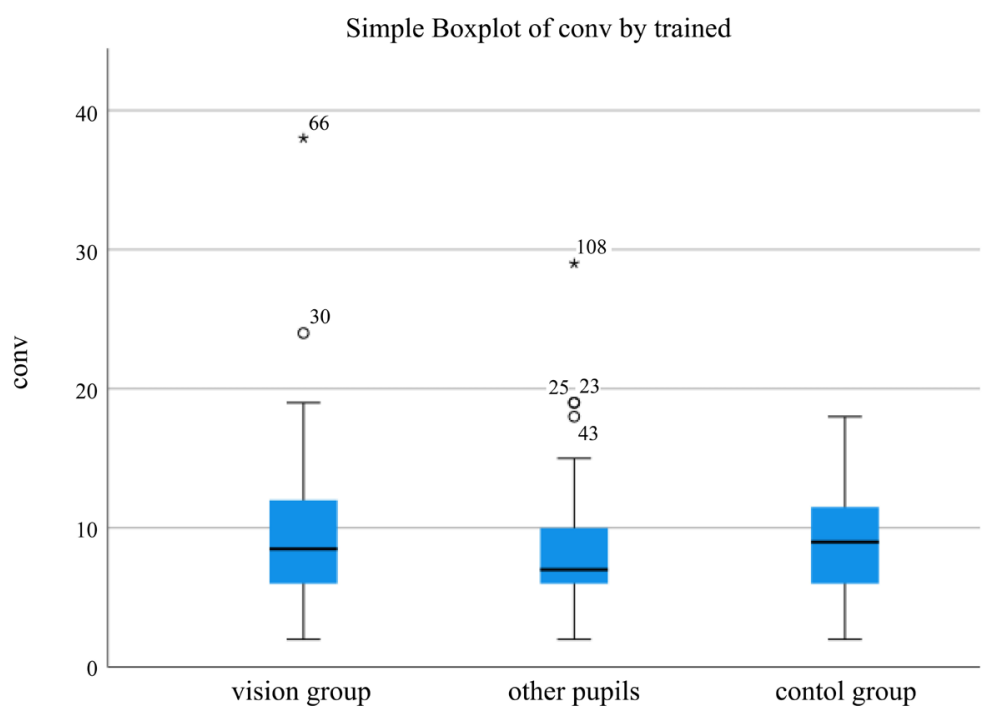

(b)

Figure 8. The distribution of (a) accommodation and (b) convergence in $\mathrm{cm}$ among the pupils in the three groups in Phase 1. (a) Accommodation in the three groups; (b) Convergence in the three groups. 


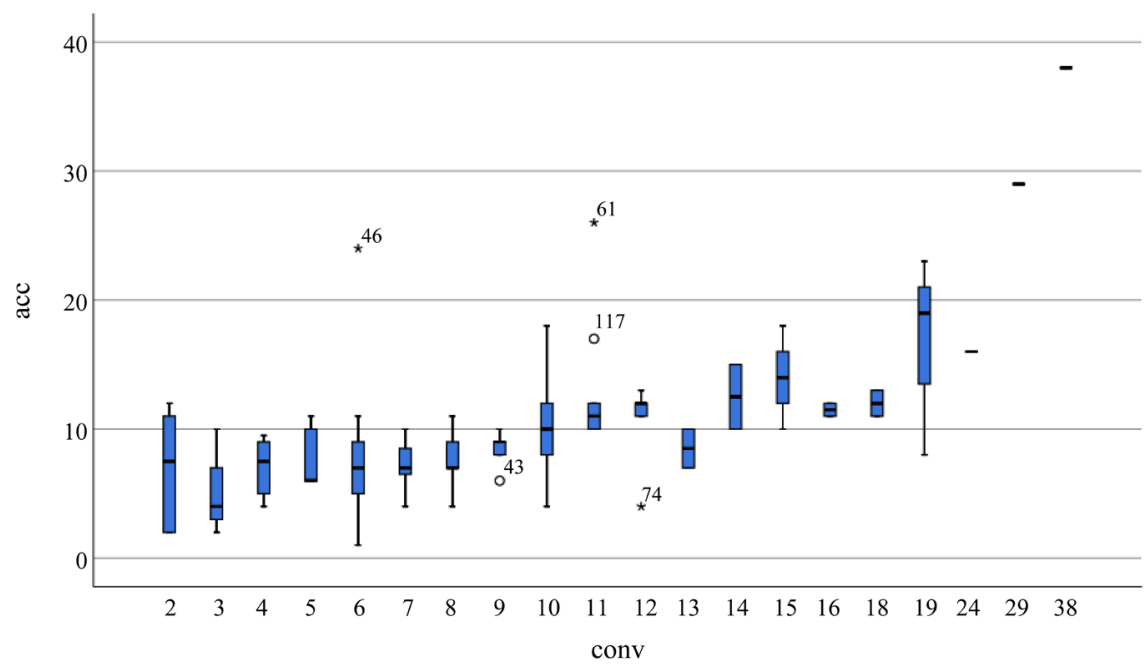

Figure 9. The boxplot show the connection between accommodation and the convergence capacity for all participants $(\mathrm{N}=104)$.

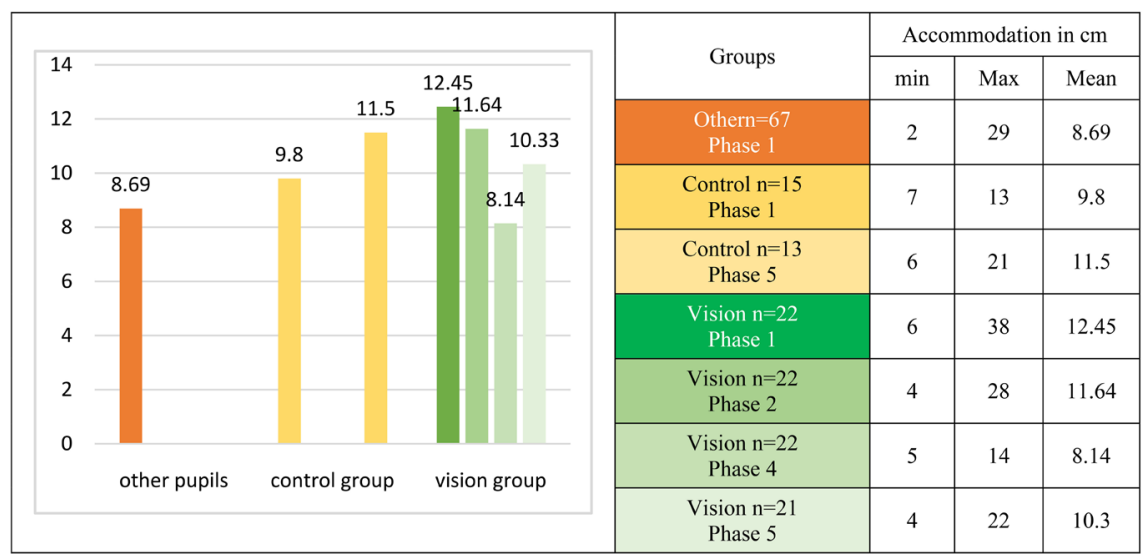

Figure 10. The min, max and mean results of accommodation for the other pupils $(\mathrm{n}=$ 67) who were tested in Phase 1 , the control group $(n=13)$ which was tested in Phase 1 and one year in Phase 5 and vision group $(n=22)$ who were tested in Phase 1 , Phase 2 (pre-intervention), Phase 4 (post-intervention) and Phase 5. The bars illustrate the means.

\subsection{Reading Speed}

The vision group $(\mathrm{n}=16)$ had a mean reading speed in Phase 1 of 81.4 words per minute; the pupils who were later invited as a control group $(\mathrm{n}=15)$ read 84.4 words per minute. The other 66 pupils (who were not assessed again), had a mean reading speed of 90.5 words per minute on this very first reading test, Figure 11.

In the boxplot diagram, Figure 11 the distribution of reading speed in each group is illustrated. Some pupils in the control group and among the other pupils were reading more than 100 words per minute. These are illustrated as outliers (Figure 12).

As can be shown in Figure 13, the pupils in the vision group had improved their reading speed after the intervention, Phase 4 , and continued to improve 
their reading throughout the year. Even though the children in the vision group started out with a lower reading speed than the control group prior to intervention, their scores for the reading speed in Phase 5 is higher than the control group, Figure 13. The larges "jump" in reading speed for the vision group was measured after the three weeks with vision lessons. Here their reading speed had increased with the mean of 10 words per minute.

Some pupils had problems reading on the screen due to light adaption-problems, therefore they could not take the reading test.

A comparison of the changes in reading speed after one year, Figure 14, shows that the vision group is now reading quicker than the control group. Their reading speed went up 16.9 words per minute compared to 1.4 words per minute of the control group. The only difference in their education this year was that the vision group had three weeks, $12-15$ hours with vision lessons in the middle of the school year.

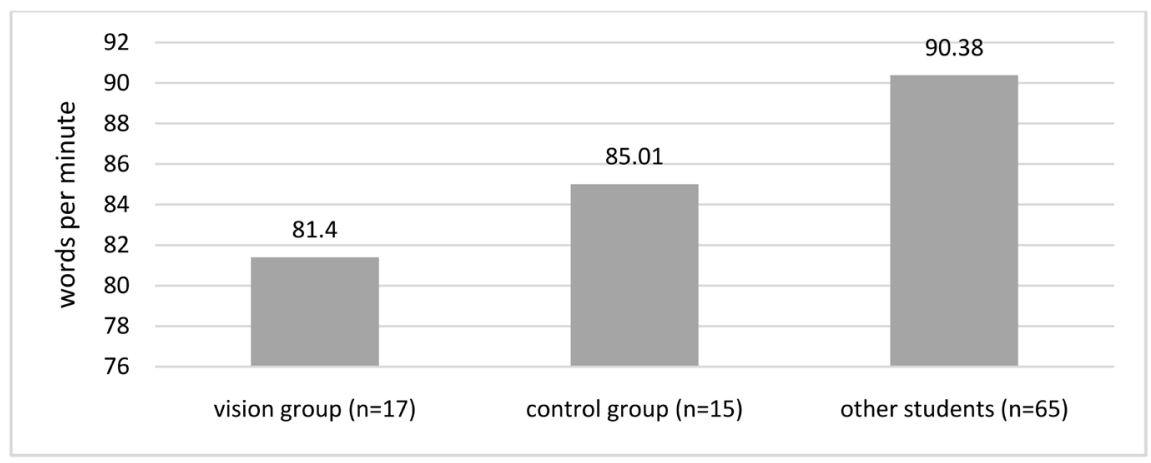

Figure 11. The reading performance in mean of words per minute in the very first test for the vision group, the control group and the other students.



Figure 12. The boxplot distribution of reading speed in the three groups in Phase 1. [Vision group $(n=17)$, other pupils $(n=65)$, control group $(n=15)$ ]. 


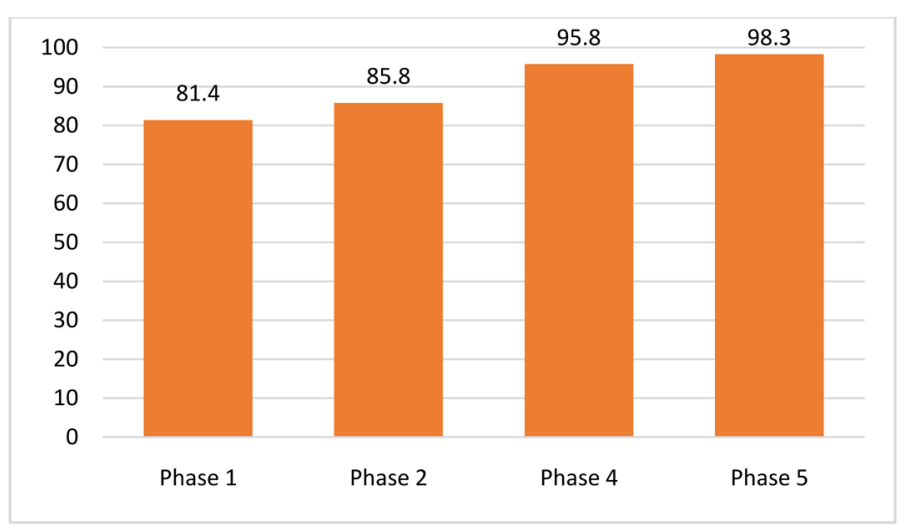

Figure 13. The reading speed in words per minute for the vision group on the different tests. There is one year between Phase 1 and Phase 5, and three weeks with intervention between Phase 2 and Phase 4.

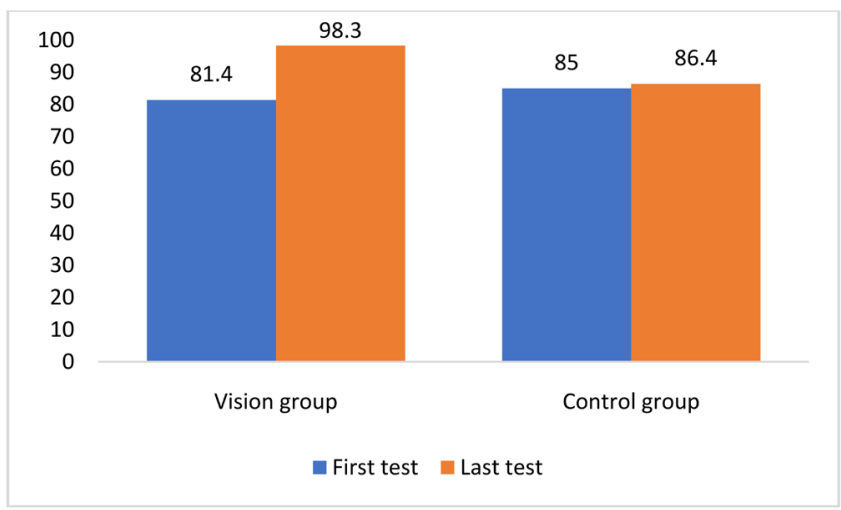

Figure 14. The reading speed for the vision group $(n=19)$ and the control group $(\mathrm{n}=14)$ in Phase 1 (blue) and one year later, Phase 5 (orange).

\section{Discussion of Results}

The results for vision assessment, visual acuity, accommodation and convergence and reading speed are discussed below.

\subsection{Visual Assessment}

In Phase 1, all pupils in Standard 5 were screened and some were selected for vision intervention. It was the intention to find the pupils who needed the intervention most but not all wanted to join the vision lessons, some with vision disturbances had a high reading speed and managed well in school. Some children with binocular problems supress one eye when working at near, mostly the not-dominant eye. This prevents double vision to occur during reading and makes it easier to function well. The problem is that they have an amblyopic eye, with reduced visual acuity, at least for near. They might even alternate between using one eye for near work and one for viewing at a distance. Normally they have reduced binocular vision.

The boxplot graphs reveal that even in the group of other students some have reduced visual acuity and weak accommodation and convergence. But 37 pupils 
were divided in a vision group $(\mathrm{n}=22)$ and a control group $(n=15)$ due to their total performance on the vision screening and reading test. The rest of the screened pupils, 104 pupils, formed the group of other pupils.

The vision problems found during the assessment were not previously detected or addressed by anybody. The reductions in accommodation and convergence support other findings that such problems in school are widespread (Borsting et al., 2003; Sterner, 2004; Sterner, Gellerstedt, \&Sjörström, 2004).

\subsection{Visual Acuity, Reading Speed and Accommodation}

There was an immediate (Phase 4) and long-term (Phase 5) effect on visual acuity, VA, at near following intervention for the vision group compared with the control group. This was noticeable half a year after the intervention even for the reading speed (Phase 5). In terms of binocular visual acuity at near and reading speed measured in words per minute, the vision group, which started out with lower scores (Phase 1), reached the same VA level at near as the control group and were reading quicker $1 / 2$ a year post intervention than the control group (Phase 5), although the control group started out with higher scores in both areas (Phase 1). Visual acuity probably increased due to exercises and training of accommodation and convergence in multiple, repetitive and intensive ways throughout the vision lessons.

Accommodation and convergence improved during the intervention (Phase 4), and even after 6 months (Phase 5) scores were still better than in the control group (Phase 5) but not as good as in Phase 4. One explanation may be that there was not long enough training to make a longer-term impact. The vision lessons went on for only three weeks. Some of the pupils are probably in need of a new period of lessons to be able to sustain accommodation and convergence capacity over time (Wilhelmsen \& Knudsen, 2020). The findings in this study are supported by other studies with regards to the effect of training of visual functions.

Wilhelmsen \& Knudsen (2020) describe in their study that structured visual stimulation can improve visual functions particularly accommodation and convergence and also binocular visual acuity. Ma et al. (2020) come to the conclusion in their study that office-based vision therapy reinforced with home exercises is effective. There is also evidence that visual training has an impact on brain areas related to reading ability in dyslexic students (Taskov \& Dushanova, 2020). Another study demonstrates that vision exercises have an impact on better visual functioning in pupils with Attention Deficit Hyperactivity Disorder, $\mathrm{ADHD}$, and even reduces some of the symptoms of the disorder (Hyung-Chel \& Hyo-Lyun, 2020). Hussaindeen et al. (2018) show that binocular disorders are frequently found in children with learning disabilities and that structured vision stimulation can improve their visual functioning. In vision lessons and vision exercises primarily ocular motor functions like accommodation and convergence, fixation and gaze jumps (saccades) and smooth pursuits, are streng- 
thened. This is probably why Balke \& Lundmark (2018) found that the short-term effect of vision training for accommodative disorder was greater than when the children were provided with passive correction such as spectacles. Refraction has little influence on strengthening the ocular motor functions. But minus and plus lenses connected in flipper glasses have shown good effect as a training tool (Sterner, 2004). Hernández-Rodríguez \& Piñero (2020) come to the conclusion that vision therapy looks promising for the treatment of amblyopia in children.

Vision therapy is usually conducted by optometrists in an office. Structured vision lessons performed in school with a vision teacher, are to a large degree developed based on pupils' individual needs of exercise level. Here it is possible to take into account even their intellectual capacity, motivation, interest and schoolwork setting as well as their functional vision. It is easier to see more children in need and to cooperate with teachers and parents (Wilhelmsen \& Knudsen, 2020).

The novel aspect in the study presented here was that training, or vision lessons, was performed in school, by qualified teachers trained extensively in vision theory, assessment and intervention procedures (Wilhelmsen \& Felder, 2020; Felder, Wilhelmsen \& Schneiders, 2021). Children were taught by teachers in their natural environment. This study supports previous findings that highly qualified teachers are able to do such type of interventions (Wilhelmsen \& Knudsen, 2020; Wilhelmsen, Aanstad \& Leirvik, 2015). Barraga (1964), a low vision teacher, improved visual functioning for children with low vision through structured vision lessons with stimulation and training. The methods used with the children in the vision group were built on similar principles and methods of her educational approaches but enhanced with new insights in the neurology of vision and ocular motor capacities.

However, there is an ongoing discussion in the field of visual impairment, optometry and ophthalmology whether vision exercises might improve visual functions. There is ample evidence that convergence and accommodation disorders can be improved with office-based vision therapy. Results are much better for in-office than home-based training for example (Scheiman, 2017). In education, there is also a controversy about teachers doing visual training or therapy (Willings, 2017). Vision therapy conducted by optometrists in an office is to date the empirically best supported method of vision therapy (Scheiman, 2017).

One possible benefit of providing structured visual stimulation and exercises in school would be for children to have easier access to such intervention. Because intact visual functions are so important for learning, problems in those areas could be identified sooner and teacher specialists in the area of vision could collaborate on site with classroom teachers for visual problems affecting learning. When $30 \%$, or even more, of pupils have unsatisfactory vision function that influence their academic learning (White et al., 2017; Wilhelmsen, 2012), it is important that schools can meet their needs for developing vision attention, 
better ocular functions and adapt their learning environment.

In Europe, Poppelreuter (1917) was the first who discovered that visual exercises can improve visual function deficits. His patients were soldiers returning from World War I with vision problems due to gun-shot wounds to the head. As we pointed out in the beginning, brain plasticity lies at the core of learning. We now, a century later, have evidence that visual losses due to diseases like glaucoma, stroke, diabetic neuropathy and brain damage can sometimes be recovered through training and non-invasive electro-stimulation (Dundon et al., 2015; Sabel \& Gudlin, 2014; Sabel et al., 2011; Wilhelmsen, 2000; Zihl, 1988; Kasten et al., 1998). Educators should be aware of such research and evaluate what this means for their practice.

\section{Implications of the Results for Practice}

Learning and development are possible because of brain plasticity. Positive and negative experiences influence the way of learning, the overall development and in the end even the personality of an individual. The brain has great capacity to change but timing is essential and therefore early intervention is very important (Shore, 2003). Children need to be taught using methods that suit them in their learning and development. They need to collect experiences so the neurological pathways can be formed and strengthened through repetition (Schiller, 2010).

The vision group received vision lessons for three weeks, which is not much when a function must be reorganized and further developed. The mean accommodation for this group showed in Phase 5 a regression which indicates the need of some pupils being in the need of more stimulation. Some may need a new period of lessons to be able to keep up the capacity and ability to stay in power over time (Wilhelmsen \& Knudsen, 2020). Some will get this chance from the teacher students working in this school.

Structured, precise, repetitive, discrete, interesting, motivating and intensive training adapted to the child's developmental stage have an impact on selected visual functions and possibly improves educational outcome such as better reading, endurance and concentration.

Vision is important for learning and thus needs to be assessed regularly. Teachers need to be knowledgeable in the area of vision so they can identify problems and refer children to service providers such as optometrists, specialised teachers or provide stimulation and vision lessons themselves when highly trained.

However, one question that needs to be further investigated is how such assessments and interventions can be practiced with validity and fidelity by specialized teachers in schools. It requires highly educated and trained teachers and a school-system with wide provisions for visual lessons to occur during the school day. Further studies must identify the benefits and possible problems of such interventions by teachers and perhaps even compare treatment results of some cases with office-based vision therapy provided by optometrists. It is also a question if some elements of vision stimulation can be embedded in regular ac- 
tivities at school and in classrooms (Wilhelmsen \& Knudsen, 2020).

\section{Limitations of the Study}

This was a small study. The assessments and intervention were conducted by different people with varying levels of expertise and experience -, professionals such as Teachers of the Visually Impaired and Vision Scientists with many years of experience and the student teachers in training. The student teachers doing the assessment and subsequent intervention were trained teachers, most of them special education teachers with various specialties. They underwent rigorous theoretical and hands-on training prior to the intervention. Nevertheless, the thematic was new to them and thus their skills or lack thereof may have influenced the intervention and the pre-and post-assessment even though they received supervision and hands-on-support during all phases of the experiment. We also did not investigate the socio-economic status of the children but because of the type of school and its location it can be carefully assumed that the pupils formed a relatively homogenous group. We also did not assess the pupils' English language ability (the students' first language was Kiswahili) which may be an important factor in educational outcome, particularly when it comes to reading progress. Children were randomly assigned to the intervention vs. control group based solely on the assessment results in the area of visual functioning and reading speed.

\section{Conclusion}

The children who were part of vision intervention group developed better visual acuity at near and increased their reading speed during three weeks of intensive vision lessons. These results give reason for optimism with regards to the shorter- and longer-term effects of structured visual stimulation and exercises on visual functions and reading. It would even be interesting to investigate how these lessons influence pupils' overall academic learning, social life and self-confidence.

\section{Funding}

The Research Council of Norway, project No: 267524/H30.

\section{Conflicts of Interest}

The authors declare no conflicts of interest regarding the publication of this paper.

\section{References}

Alramis, A., Roy, A., Christian, L., \& Niechwiej-Szwedo, E. (2016). Contribution of Binocular Vision to the Performance of Complex Manipulation Tasks in 5-13 Years Old Visually-Normal Children. Human Movement Science, 46, 52-62. https://doi.org/10.1016/j.humov.2015.12.006

Balke, M., \& Lundmark, P. (2018). Comparison of the Short-Term Effect after 6 Weeks of 
Treatment of Accommodative Infacility with Either +0.5 D Addition in Spectacles or Accommodation Exercises with Hard Chart. Investigative Ophthalmology \& Visual Science, 59, 2944.

Barraga, N. (1964). Increased Visual Behavior in Low Vision Children. Research Series, no 13, New York, NY: American Foundation for the Blind.

Birch, E. (2013). Amblyopia and Binocular Vision. Progress in Retinal and Eye Research, 33, 67-84. https://doi.org/10.1016/j.preteyeres.2012.11.001

Björklund, D. F., \& Causey, K. B. (2017). Children's Thinking: Cognitive Development and Individual Differences (6th ed.). Los Angeles, CA: SAGE.

Borsting, E., Rouse, M. W., Deland, P. N., Hovett, S., Kimura, D., \& Park, M. (2003). Association of Symptoms and Convergence and Accommodative Insufficiency in School-Age Children. Optometry, 74, 25-34

Bucci, M. P., Brémond-Gignac, D., \& Kapoula, Z. (2008). Poor Binocular Coordination of Saccades in Dyslexic Children. Graefe's Archive for Clinical and Experimental Ophthalmology, 246, 417-428. https://doi.org/10.1007/s00417-007-0723-1

Coetzee, D., \& Pienaar, A. E. (2013). The Effect of Visual Therapy on the Ocular Motor Control of Seven-to Eight-Year-Old Children with Developmental Coordination Disorder (DCD). Research in Developmental Disabilities, 34, 4073-4084.

https://doi.org/10.1016/j.ridd.2013.08.036

Cyvin, M., \& Wilhelmsen, G. B. (2008). An Improved Vision the Basis for Motor, Language and Social Development. [Et forbedret syn, grunnlag for motorisk, språklig og sosial utvikling.] Spesialpedagogikk, 3, 28-34.

Deng, L., Gwiazda, J., \& Thorn, F. (2010). Children's Refractions and Visual Activities in the School Year and Summer. Optometry and Vision Science, 87, 406-413. https://doi.org/10.1097/OPX.0b013e3181da8a85

Dundon, N. M., Bertini, C., Làdavas, E., Sabel, B. A., \& Gall, C. (2015). Visual Rehabilitation: Visual Scanning, Multisensory Stimulation and Vision Restoration Trainings. Frontiers in Behavioral Neuroscience, 9, 192. https://doi.org/10.3389/fnbeh.2015.00192

Felder, M., Wilhelmsen, G., \& Schneiders, K. (2021). Developing "Vision-for-Learning” Competencies among Teachers in Tanzania-An Innovative Higher Education Initiative. Creative Education, 12, 82-102. https://doi.org/10.4236/ce.2021.121007

Fernández-Montero, A., Olmo-Jimenez, J. M., Olmo, N., Bes-Rastrollo, M., Moreno-Galarraga, L., Moreno-Montañés, J., \& Martínez-González, M. A. (2015). The Impact of Computer Use in Myopia Progression: A Cohort Study in Spain. Preventive Medicine, 71, 67-71. https://doi.org/10.1016/j.ypmed.2014.12.005

Hernández-Rodríguez, C. J., \& Piñero, D. P. (2020). Active Vision Therapy for Anisometropic Amblyopia in Children: A Systematic Review. Journal of Ophthalmology, 2020, Article ID: 4282316. https://doi.org/10.1155/2020/4282316

Hussaindeen, J. R., Shah, P., Ramani, K. K., \& Ramanujan, L. (2018). Efficacy of Vision Therapy in Children with Learning Disability and Associated Binocular Vision Anomalies. Journal of Optometry, 11, 40-48. https://doi.org/10.1016/j.optom.2017.02.002

Hyung-Chel, C., \& Hyo-Lyun, R. (2020). The Effect of Convergence Vision Therapy on Symptoms and Visual Perception in Children with ADHD Tendency. Journal of the Korea Convergence Society, 11, 59-71. https://doi.org/10.15207/JKCS.2020.11.7.059

Kasten, E., Wüst, S., Behrens-Baumann, W., \& Sabel, B. A. (1998). Computer-Based Training for the Treatment of Partial Blindness. Nature Medicine, 4, 1083-1087.

https://doi.org/10.1038/2079 
Kelly, K. R., Cheng-Patel, C. S., Jost, R. M., Wang, Y.-Z., \& Birch, E. (2019). Fixation Instability during Binocular Viewing in Anisometropic and Strabismic Children. Experimental Eye Research, 183, 29-37. https://doi.org/10.1016/j.exer.2018.07.013

Lane, K. (2005). Developing Ocular Motor and Visual Perceptual Skills. Thorofare: SLACK Incorporated.

Lillard, A. S., \& Erisir, A. (2011). Old Dogs Learning New Tricks: Neuroplasticity beyond the Juvenile Period. Developmental Review, 31, 207-239. https://doi.org/10.1016/j.dr.2011.07.008

Lin, Z., Vasudevan, B., Jhanji, V., Mao, G. Y., Gao, T. Y., Wang, F. H., \& Liang, Y. B. (2014). Near Work, Outdoor Activity, and Their Association with Refractive Error. Optometry and Vision Science, 91, 376-382. https://doi.org/10.1097/OPX.0000000000000219

Ma, M., Kang, Y., Chen, C., Su, C., \& Tian, Z. (2020). Vision Therapy for Intermittent Exotropia: A Case Series. Journal of Optometry. (In Press) https://doi.org/10.1016/j.optom.2020.05.006

Miles, W. R. (1929). Ocular Dominance Demonstrated by Unconscious Sighting. Journal of Experimental Psychology, 12, 113-126. https://doi.org/10.1037/h0075694

Narayanasamy, S., Vincent, S.J., Sampson, G.P., \& Wood, J.M. (2016). Visual Demands in Modern Australian Primary School Classrooms. Clinical and Experimental Optometry, 99, 233-240. https://doi.org/10.1111/cxo.12365

Orfield, A. (2007). Eyes for Learning. Preventing and Curing Vision Related Learning Problems. Toronto: Rowman \& Littlefield Education.

Poppelreuter, W. (1917/1990) Disturbances of Lower and Higher Visual Capacities Caused by Occipital Damage. Oxford: Oxford Scholarship, English Edition 1990.

Sabel, B. A., \& Gudlin, J. (2014). Vision Restoration Training for Glaucoma: A Randomized Clinical Trial. JAMA Ophthalmology, 132, 381-389.

https://doi.org/10.1001/jamaophthalmol.2013.7963

Sabel, B. A., Henrich-Noack, P., Fedorov, A., \& Gall, C. (2011). Vision Restoration after Brain and Retina Damage: The "Residual Vision Activation Theory". Progress in Brain Research, 192, 199-262. https://doi.org/10.1016/B978-0-444-53355-5.00013-0

Scheiman, M. M. (2018). 2017 Glenn A. Fry Award Lecture: Establishing an Evidence-Based Literature for Vision Therapy-A 25-Year Journey. Optometry and Vision Science, 95, 632-642. https://doi.org/10.1097/OPX.0000000000001257

Schiller, P. (2010). Early Brain Development Research Review and Update. Brain Development, 28-30.

Shore, R. (2003). Rethink the Brain: New Insights into Early Development. New York, NY: Families and Work Institute.

Sterner B., Gellerstedt, M., \& Sjörström, A. (2004). The Amplitude of Accommodation in 6-10 Year-Old Children-Not as Good as Expected! Ophthalmic and Physiological Optics, 24, 246-251. https://doi.org/10.1111/j.1475-1313.2004.00201.x

Sterner, B. (2004). Ocular Accommodation. Studies of Amplitude, Insufficiency, and Facility Training in Young School Children. Doctoral Thesis, Gothenburg: University of Gothenburg.

Taskov, T., \& Dushanova J. (2020). Reading-Network in Developmental Dyslexia before and after Visual Training. Symmetry, 12, 1842. https://doi.org/10.3390/sym12111842

White, S. L. J., Wood, J. M., Black, A. A., \& Hopkins, S. (2017). Vision Screening Outcomes of Grade 3 Children in Australia: Differences in Academic Achievement. International Journal of Educational Research, 83, 154-159. 
https://doi.org/10.1016/j.ijer.2017.03.004

Wilhelmsen, G. B. (2000). Vision Problems Due to Stroke. A Survey of Vision Functions and the Effect of Vision Training. [Visuelle forstyrrelser etter hjerneslag. En undersøkelse av synsfunksjonen og effekten av synstrening]. Thesis for Dr. Scientiarum, Oslo: University of Oslo.

Wilhelmsen, G. B. (2012). Children's Functional Vision. [Barns funksjonelle syn. Gir synsvansker som ikke klassifiseresetter ICD-10 behov for tiltak?] Bergen: Høgskolen i Bergen.

Wilhelmsen, G. B., \& Felder, M. (2020). Learning Is Visual: Why Teachers Need to Know about Vision [Online First]. London: IntechOpen.

https://www.intechopen.com/online-first/learning-is-visual-why-teachers-need-to-kno w-about-vision

Wilhelmsen, G. B., \& Knudsen, E. (2020). Reading Starts as a Vision Process. In B. Hvidsten, I. Kuginyte-Arlauskiene, \& G. Söderlund (Eds), Adapted Training and Special Needs Education in Theory and Practice [Tilpasset Opplæring og Spesialpedagogikk i teori og praksis]. Bergen: Fagbokforlaget.

Wilhelmsen, G. B., Aanstad, M. L., \& Leirvik, E. I. B. (2015). Implementing Vision Research in Special Needs Education. Support for Learning, 30, 134-149.

https://doi.org/10.1111/1467-9604.12083

Willings, C. (2017). Vision Therapy Controversy.

https://www.teachingvisuallyimpaired.com/vision-therapy-controversy.html

Zihl, J. (1988). Homonyme Hemianopsie und ihre Rehabilitation. Klinische Monatsblätter für Augenheilkunde, 192, 555-558. https://doi.org/10.1055/s-2008-1050177 